\title{
Effects of increasing flow rate on aortic stenotic indices: evidence from percutaneous transvenous balloon dilatation of the mitral valve in patients with combined aortic and mitral stenosis
}

\author{
Tsung-Ming Lee, Shen-Fang Su, Ming-Fong Chen, Chiau-Suong Liau, Yuan-Teh Lee
}

\begin{abstract}
Objectives-To investigate the effects of transvalvar flow rate on aortic valve resistance and valve area after percutaneous transvenous balloon dilatation of the mitral valve in a homogeneous group of patients with rheumatic heart disease.

Design-Retrospective analysis of 12 patients with combined aortic and mitral stenosis who had undergone balloon dilatation of the mitral valve over a period of 9 years.

Setting-Tertiary referral centre.

Patients-Twelve (8 women, 4 men; mean (SD) age 37 (9)) of 227 consecutive patients with critical mitral stenosis undergoing transvenous balloon dilatation of the mitral valve in the centre also had aortic stenosis, defined as a transaortic pressure gradient of more than $25 \mathrm{~mm} \mathrm{Hg}$ measured at a catheterisation study before valvuloplasty.
\end{abstract}

Interventions-Echocardiographic variables (mitral valve area measured by the pressure half-time method and planimetry, and the aortic valve area derived from the continuity equation) and haemodynamic measurements (cardiac output, left ventricular mean systolic pressure, aortic mean pressure, transaortic valve pressure gradient, mitral valve and aortic valve areas derived from the Gorlin formula, and aortic valve resistance) were assessed before and after transvenous balloon dilatation of the mitral valve. Follow up catheterisation to measure haemodynamic variables was performed one week after mitral valvuloplasty.

Results-Mean transaortic flow rate increased $33 \%$ after mitral valvuloplasty (from 198 (68) to 254 (41) $\mathrm{ml} / \mathrm{s}, P=$ $0 \cdot 002)$. Aortic valve areas derived from the Gorlin formula were significantly increased from $0.57(0.12)$ to $0.73(0.14)$ $\mathbf{c m}^{2}(P=0.006)$ after mitral valvuloplasty. However, aortic valve area and valve resistance derived from the continuity equation were independent of the increase in flow rate after mitral valvuloplasty (from $1.29(0.35)$ to $1.30(0.29) \mathrm{cm}^{2}$ and from $317(65)$ to 259 (75) dyn $\cdot \mathrm{s}^{\cdot} \mathrm{cm}^{-5}$, both $P=$ NS).

Conclusion-The Gorlin-derived aortic valve area tends to be flow-dependent, and continuity equation-derived aortic valve area and catheterisation-derived valve resistance seem to be less flow- dependent. In patients with combined mitral and aortic stenosis, these flowindependent indices are important for decision-making.

(Heart 1996;76:490-494)

Keywords: aortic stenosis; mitral stenosis; valvuloplasty; valve resistance.

Various methods can be used to determine aortic valve area. However, haemodynamic determination of valve area by the Gorlin formula $^{1}$ is often used to gauge the severity of aortic valve stenosis. ${ }^{2}$ The accuracy of this formula for assessment of aortic valve area has been challenged. ${ }^{34}$ Several groups have indicated that the calculated valve area varies directly with cardiac output, ${ }^{5-8}$ and that an increased transvalvar flow rate will increase the calculated valve area. The dependence of calculated valve area on transvalvar flow rates seems to be particularly important when flow rates are low; this may result in overestimation of the severity of aortic stenosis, especially in patients with combined mitral stenosis.

Aortic valve area derived from the Doppler continuity equation and haemodynamically derived valve resistance are viewed as indices of the severity of aortic stenosis that are less flow-dependent. The Gorlin equation measures anatomical valve area by assuming that it maintains a constant ratio with the flowdependent coefficient of orifice contraction. However, the continuity equation measures the effective orifice area (the area of the vena contracta) without making any assumptions. Haemodynamically derived valve resistance (the simple ratio of mean transvalvar pressure difference to mean flow rate) was proposed as an index of stenosis many years ago. .11 $^{-11}$ Studies have shown that when the pressure gradient was varied the Gorlin-calculated valve area changed at least three times more than resistance. Valve resistance seems to be less flow-dependent. ${ }^{1213}$ However, in dogs Burwash et $a l^{67}$ showed a degree of flowdependence of the aortic valve area derived from the continuity equation and of valve resistance that was similar to the Gorlinderived aortic valve area.

We have investigated the effect of increasing transvalvar flow rate on aortic valve areas derived from the Gorlin and Doppler echocardiography continuity equations and on haemodynamically measured valve resistance. 


\section{Patients and methods}

PATIENTS

Between July 1987 and May 1995, 227 patients with symptomatic mitral stenosis underwent balloon dilatation of the mitral valve at the National Taiwan University Hospital. Twenty one patients had concomitant transaortic mean pressure gradients $\geqslant 25$ $\mathrm{mm} \mathrm{Hg}$ measured during the prevalvuloplasty catheterisation study. Surgical valve replacement was suggested for all these patients. The 12 patients who were reluctant to undergo valve replacement became the study group. All patients signed informed consent sheets for balloon dilatation of the mitral valve. The eight women and four men were aged 37 (9) (SD) (range 20-61).

\section{ECHOCARDIOGRAPHIC ASSESSMENT}

Study patients had cross sectional echocardiography with Doppler colour flow mapping one to two days before and one to three days after balloon dilatation of the mitral valve. A Hewlett-Packward Sonos 1000 or 1500 was used. The severity of mitral regurgitaiton and aortic regurgitation was assessed as described by Abascal et al ${ }^{14}$ and Otto et al. ${ }^{15}$ Mitral valve area was calculated by the Doppler pressure half-time method ${ }^{16}$ and planimetry. In the planimetry method the smallest orifice of the mitral valve was identified in the parasternal short axis view and the valve area was measured at maximum opening in diastole on a freeze-frame image. None of the patients had an echocardiographic valve score of $>8$ on a scale of $16 .{ }^{15}$ Aortic valve area was calculated by continuity equation ${ }^{14}$ as follows:

$$
\mathrm{Ac}=\mathrm{A}_{\mathrm{LVOT}} \cdot \mathrm{V}_{\mathrm{LVOT}} / \mathrm{V}_{\max }
$$

where, $A c=$ aortic valve area, $A_{L v o t}=$ the cross sectional area of the left ventricular outflow tract, $\mathrm{V}_{\mathrm{LVOT}}=$ flow velocity in the left ventricular outflow tract before the aortic valve, obtained by the pulsed Doppler method, and $\mathrm{V}_{\max }=$ the highest maximal poststenotic jet velocity, recorded by continuous wave Doppler from the apical view. Measurements in patients with atrial fibrillation were averaged for five consecutive beats. Video images were recorded for off-line analysis.

Table 1 Measurements (mean (SD)) before and after balloon dilatation of the mitral valve in the 12 study patients

\begin{tabular}{|c|c|c|c|}
\hline Variables & Before PTMV & After PTMV & Pvalue \\
\hline $\mathrm{HR}\left(\min ^{-1}\right)$ & $72(8)$ & $73(6)$ & NS \\
\hline $\mathrm{CO}(1 / \mathrm{min})$ & $3.6(0 \cdot 1)$ & $4 \cdot 2(0 \cdot 5)$ & 0.01 \\
\hline $\mathrm{CI}\left(1 / \mathrm{min} \cdot \mathrm{m}^{2}\right)$ & $2 \cdot 2(0 \cdot 3)$ & $2 \cdot 6(0 \cdot 3)$ & 0.01 \\
\hline Flow rate $(\mathrm{ml} / \mathrm{s})$ & $198(68)$ & $254(41)$ & 0.002 \\
\hline Transaortic mean pressure & & & \\
\hline gradient $(\mathrm{mm} \mathrm{Hg})$ & $34(7)$ & 37 (13) & 0.006 \\
\hline Diastolic ejection time (s/beats) & $0.473(0.042)$ & $0.438(0.062)$ & NS \\
\hline Systolic ejection time (s/beats) & $0.345(0.035)$ & $0.308(0.045)$ & 0.03 \\
\hline \multicolumn{4}{|l|}{ Mitral valve area $\left(\mathrm{cm}^{2}\right)$ : } \\
\hline Doppler $\mathrm{t} 1 / 2$ & $0 \cdot 86(0 \cdot 17)$ & $1 \cdot 63(0 \cdot 22)$ & $<0.0001$ \\
\hline Planimetry & $0.78(0.18)$ & $1.73(0.21)$ & $<0.0001$ \\
\hline Gorlin formula & $0.83(0.12)$ & $1.48(0.26)$ & $<0.0001$ \\
\hline \multicolumn{4}{|l|}{ Aortic valve area $\left(\mathrm{cm}^{2}\right)$ : } \\
\hline Continuity equation & $1.29(0.35)$ & $1.30(0 \cdot 29)$ & NS \\
\hline Gorlin formula & $0.57(0.12)$ & $0.73(0 \cdot 14)$ & 0.006 \\
\hline Aortic valve resistance $\left(\right.$ dyn $\cdot \mathrm{s}^{\bullet} \mathrm{cm}^{-5}$ ) & $317(65)$ & $259(75)$ & NS \\
\hline
\end{tabular}

$\mathrm{CI}$, cardiac index; CO, cardiac output; PTMV, percutaneous transvenous mitral valvuloplasty.
CATHETERISATION

Before balloon valvuloplasty, diagnostic right and left catheterisation was performed from a femoral approach. Baseline heart rate, cardiac output, and left ventricular and systemic arterial pressure were measured. Cardiac output was determined by the thermodilution method in triplicate or quadruplicate by injecting $10 \mathrm{ml}$ of ice-cold saline solution. Left ventricular and femoral artery pressures were measured with simultaneous recordings by a catheter and sidearm sheath. To spare patients the added discomfort and risk of a second aortic catheterisation, femoral artery pressure was used instead of pressure in the ascending aorta. ${ }^{17}$ Simultaneously measured left ventricular-femoral artery gradients represented transaortic pressure gradients. After baseline prevalvuloplasty haemodynamic measurements were obtained, transseptal puncture was performed. Balloon mitral valvuloplasty was performed with an Inoue balloon catheter (26-28 mm). Sequential inflations were performed at increasing diameters until a balloon waist disappeared. After balloon mitral valvuloplasty, right and left heart catheterisation was repeated by the same cardiac catheterisation procedure. The shunt ratio of the atrial septal defect was calculated from the oxygen saturation differences. Valve areas were calculated using the Gorlin formula ${ }^{1}$ :

Aortic valve area $\left(\mathrm{cm}^{2}\right)=\mathrm{CO} / 44 \cdot 3 \cdot \mathrm{HR}$. SEP.(transaortic mean pressure gradient) ${ }^{1 / 2}$ where $\mathrm{CO}$ is cardiac output ( $\mathrm{ml} / \mathrm{min}), \mathrm{HR}$ is heart rate (beats/min), and SEP is systolic ejection period (seconds/beat).

Mitral valve area $\left(\mathrm{cm}^{2}\right)=\mathrm{CO} / 38 \cdot \mathrm{HR}$ DEP.(transmitral mean pressure gradient) ${ }^{1 / 2}$ where $\mathrm{CO}$ is cardiac output ( $\mathrm{ml} / \mathrm{min}), \mathrm{HR}$ is heart rate (beats/min), and DEP is diastolic ejection period (seconds/beat).

Aortic valve resistance $\left(\right.$ dyn $\left.\cdot \mathrm{s} \cdot \mathrm{cm}^{-5}\right)=$ 1333.mean PG.HR.SEP/CO where PG is transaortic pressure gradient ( $\mathrm{mm} \mathrm{Hg}$ ), $\mathrm{HR}$ is heart rate (beats/min), SEP is systolic ejection period (seconds/beat), and CO is cardiac output $(\mathrm{ml} / \mathrm{min})$. Follow up catheterisation was performed for haemodynamic measurements and cardiac output one week after the first catheterisation.

\section{STATISTICAL ANALYSIS}

Values are expressed as mean (SD). Changes in echocardiographic and haemodynamic variables were evaluated with paired $t$ test. Catheterisation and Doppler measures of the severity of aortic stenosis were compared by linear regression. A probability $(P)$ value of less than 0.05 was regarded as significant.

\section{Results}

EFFECT OF CHANGING FLOW RATE ON AORTIC VALVE AREA AND VALVE RESISTANCE

Transthoracic echocardiographic and haemodynamic variables before and after balloon mitral valvuloplasty are shown in table 1 . Mean transaortic pressure gradient before valvuloplasty was 34 (7) $\mathrm{mm} \mathrm{Hg}$. Mitral valve areas measured by planimetry, the Doppler 
pressure half-time method, and Gorlin formula were significantly increased from 0.78 $(0.18)$ to $1.73(0.21) \mathrm{cm}^{2}$, from $0.86(0.17)$ to $1.63(0.22) \mathrm{cm}^{2}$, and from $0.83(0.12)$ to 1.48 $(0.26) \mathrm{cm}^{2}$, respectively (all $\mathrm{P}<0.0001$ ). In response to mitral valvuloplasty, cardiac output and cardiac index significantly increased from $3.6(0.1)$ to $4.2(0.5) 1 / \mathrm{min}$ and from 2.2 $(0.3)$ to $2.6(0.3) 1 / \mathrm{min}$ per $\mathrm{m}^{2}$ (both $\mathrm{P}=$ 0.01 ), predominantly because of the increase in stroke volume instead of heart rate. The systolic ejection time was significantly decreased after mitral valvuloplasty. Mean transaortic flow rate increased $33 \%$ from 198 (68) to 254 (41) $\mathrm{ml} / \mathrm{s}(P=0.002)$. The flow rate at follow up catheterisation $(265(46) \mathrm{cm} / \mathrm{s})$ did not show significant change compared with that immediately after balloon mitral valvuloplasty. The Gorlin-derived aortic valve area ranged from 0.42 to $0.85 \mathrm{~cm}^{2}$ with a mean of 0.57 $(0 \cdot 12) \mathrm{cm}^{2}$ before mitral valvuloplasty, and increased to a mean of $0.73(0.14) \mathrm{cm}^{2}$ after mitral valvuloplasty $(P=0.006)$. The aortic valve area derived from the continuity equation remained steady at $1.29(0.35)$ and 1.30 $(0 \cdot 29) \mathrm{cm}^{2}$ respectively. The correlation coefficient for Gorlin-derived and continuity equation-derived aortic valve areas was 0.57 (Gorlin valve area $=0.185$. continuity equation valve area $+0.334, \operatorname{SEE}=0.099 \mathrm{~cm}^{2}$ ) before valvuloplasty. However, the correlation coefficient was 0.75 after valvuloplasty (Gorlin valve area $=0.351 \cdot$ continuity equation valve area +0.276, SEE $=0.097 \mathrm{~cm}^{2}$ ). Aortic valve resistance was not significantly changed after valvuloplasty (317 (65) v 259 (75) dyn $\cdot \mathrm{s} \cdot \mathrm{cm}^{-5}$, $\mathrm{P}=\mathrm{NS}$ ).

\section{Discussion}

EFFECTS OF FLOW RATE ON STENOTIC INDICES In this study aortic valve area derived from the Doppler echocardiographic continuity equation and haemodynamically derived valve resistance were less flow dependent than the Gorlin-derived aortic valve area. Several previous studies consistently found that Gorlin valve areas changed with volume flow rate both in vitro ${ }^{18}$ and in patients. ${ }^{19} 20$ Gorlin valve areas increased $19 \%$ to $50 \%$ when transvalvar volume flow rate increased by $50 \%$. In the current study there was a $33 \%$ increase of transaortic flow rate and a $27 \%$ increase in Gorlin-derived aortic valve area after balloon mitral valvuloplasty. The change in Gorlinderived valve areas may partly be the result of a "true" change in anatomical area. Video images of in vitro pulsatile flow models have shown that the valve orifice does increase with increasing volume flow rate, ${ }^{21}{ }^{22}$ presumably because greater flow-mediated force is delivered to the non-rigid valve. However, changes in Gorlin-derived valve areas caused by changes in volume flow rate in patients here can not be totally explained by anatomical flow-dependent changes because rheumatic aortic valves have fixed valves even at the early stage of rheumatic heart disease. Discharge coefficients in the Gorlin constant were assumed to be fixed which may not accurately reflect stenotic valve geometry. ${ }^{4}$ Indeed, the discharge coefficients have never been validated in native aortic valve stenosis.

Previous studies of the flow dependence of the continuity equation-derived valve area and haemodynamically derived valve resistance had inconsistent results (table 2). ${ }^{568}$ Several studies showed constant continuity equationderived valve areas and valve resistance despite an increase in volume flow rate, as we did in the present study. However, the continuity equation-derived valve areas were shown to be flow-dependent in an in vitro study ${ }^{21}$ and in patients. ${ }^{63}$ There may be an explanation for these discordant observations. First, the aortic stenosis studied was of different severity and cause. Table 2 shows that Cannon et $a l^{5}$ reported that a heterogeneous group of patients with severe aortic stenosis and clinical symptoms had constant continuity-equation valve areas and valve resistance with increases in volume flow rate. When severe aortic stenosis develops, especially that associated with degeneration, aortic valves become immobile, heavily calcified, and non-flexible. Immobile aortic valves are not likely to respond to flow rate changes. Thus orifice areas would not be expected to change when volume flow rate increases in patients with severe aortic stenosis. Patients with severe and immobile aortic valves will have constant continuity equation valve areas. In this study, because the patients were relatively young and had mild aortic stenosis, their aortic valves were probably more flexible. However, this is the first study of indices of aortic valve stenosisc during flow rate changes in a homogeneous group of rheumatic heart disease patients. Compared with degenerative aortic stenosis, rheumatic aortic stenosis is characterised by a tricuspid valve with fusion of one to three commissures and densely fibrotic cusps resulting in fixed aortic valves during the early stage of rheumatic heart disease. Findings showed

Table 2 Discordant results of flow-independence of aortic valve area and valve resistance

\begin{tabular}{|c|c|c|c|c|c|c|c|c|c|}
\hline Study & No & Symptoms & Method & Intervention & $\begin{array}{l}C O \\
(\operatorname{limin})\end{array}$ & $\begin{array}{l}\text { Flow rate } \\
(\mathrm{mlls})\end{array}$ & $\begin{array}{l}P G \\
(m m \mathrm{Hg})\end{array}$ & $\begin{array}{l}\text { Flow } \\
\text { dependent }\end{array}$ & $\begin{array}{l}\text { Flow } \\
\text { independent }\end{array}$ \\
\hline $\begin{array}{l}\text { Cannon et al } l^{5 \star} \\
\text { Burwash et al }\end{array}$ & $\begin{array}{r}4 \\
66\end{array}$ & $\begin{array}{l}\text { Yes } \\
\text { No }\end{array}$ & $\begin{array}{l}\text { Cath } \\
\text { Echo }\end{array}$ & $\begin{array}{l}\text { Nitroprusside } \\
\text { Exercise }\end{array}$ & $50 \%$ & $\overline{24} \%$ & $\begin{array}{l}-7 \% \\
36 \%\end{array}$ & \multirow{3}{*}{$\begin{array}{l}\text { G-AVA } \\
\text { C-AVA, } \\
\text { Valve resistance } \\
\text { G-AVA } \\
\text { G-AVA }\end{array}$} & Valve resistance \\
\hline Casale $e t a l^{8}$ & 12 & - & Cath & Dobutamine & $38 \%$ & $34 \%$ & $25 \%$ & & $\begin{array}{l}\text { C-AVA, } \\
\text { Valve resistance }\end{array}$ \\
\hline This study & 12 & Yes & Cath & PTMV & $19 \%$ & $33 \%$ & $9 \%$ & & $\begin{array}{l}\text { C-AVA, } \\
\text { Valve resistance }\end{array}$ \\
\hline
\end{tabular}

*The values were calculated from mean values of cardiac output and pressure gradient. - , no data available; C-AVA, aortic valve area derived from the continuity equation; cath, catheterisation; CO, cardiac output; echo, echocardiography; G-AVA, Gorlin-derived aortic valve area; PG, pressure gradient; PTMV, percutaneous transvenous mitral valvuloplasty. 
constant continuity equation valve areas similar to those in patients with severe aortic stenosis. Burwash et $a^{67}$ studied patients with non-critical aortic stenosis without symptoms who had more flexible valves, which explains why their continuity equation valve areas were flow-dependent. These observations support the hypothesis that the severity and cause of aortic stenosis are important in the interpretation of severity indices. Second, the discrepancy may relate in part to methodological differences. Burwash et $\mathrm{al}^{67}$ demonstrated the flow dependence of valve resistance calculated from Doppler echocardiography instead of from conventional invasive catheterisation. The inherent limitations of echocardiography in measuring simultaneous transvalvar and left ventricular outflow tract velocities and sampling sites before pressure recovery may have confounding effects on conclusions.

\section{POTENTIAL LIMITATIONS}

There were several potential limitations in this study. First, atrial fibrillation was present in nine of the 12 subjects. This would be expected to affect the accuracy of valve area (Gorlin and continuity equation) and valve resistance. It became difficult to obtain the simultaneous pressure gradients and flow measurements required for accurate invasive measurement of indices of stenosis. Second, in this study all patients had variable degrees of mild to moderate aortic regurgitation of a rheumatic nature which would cause underestimation of cardiac output by the thermodilution method. The Gorlin method overestimates the severity of stenosis in false low cardiac output states. This may in part explain the great differences between aortic valve areas derived from the Gorlin and continuity equations. Third, the Gorlin aortic valve area and continuity equation valve area were not derived simultaneously. Though transvalvar flow had changed between the times of the two Gorlin aortic valve area measurements, we do not know whether transvalvar flow rate was different at the time of the two continuity equation valve area measurements. However, the flow rates at follow up catheterisation one week after balloon mitral valvuloplasty were not significantly different compared with those measured immediately after balloon mitral valvuloplasty. Thus the difference of measurement timing is unlikely to have affected the results. Fourth, there is no "gold standard" measurement of true anatomical valve area in vivo with which to compare the observed valve area. Thus the real increase of anatomical valve area or its reflection in flow dynamics can not be determined. Fifth, the study group is small; nevertheless, it does suggest a new approach to stenotic indices after balloon mitral valvuloplasty. These findings need to be be confirmed in a larger study.

\section{CLINICAL IMPLICATIONS}

The flow-dependence of the Gorlin aortic valve area may significantly influence clinical decision-making. A critical aortic area calculated by Gorlin formula may not be a "true" critical lesion, especially when flow is low as it is when aortic stenosis is combined with mitral stenosis. Before patients with combined aortic and mitral stenosis are subjected to double valve replacement or valvuloplasty, aortic valve areas derived from the continuity equation and haemodynamially derived valve resistance (which are less flow-dependent) should be measured to reflect the true severity of aortic stenosis.

\section{CONCLUSIONS}

In patients with combined aortic and mitral stenosis who have low cardiac output, the Gorlin-derived aortic valve area tends to overestimate the severity of aortic stenosis. The aortic valve area derived from the Doppler echo continuity equation and haemodynamically derived valve resistance seem less flowdependent and more useful clinically, especially in patients with immobile valves.

1 Gorlin R, Gorlin SG. Hydraulic formula for calculation of the area of the stenotic mitral valve, other cardiac valves, and central circulatory shunts. I. Am Heart f 1951;41: $1-29$.

2 Carabello BA. Timing of surgery in mitral and aortic stenosis. Cardiol Clin 1991;9:229-38.

3 Cannon SR, Richards KL, Crawford M. Hydraulic estimation of stenotic orifice area: a correlation of the Gorlin formula. Circulation 1985;71:1170-8.

4 Segal J, Lerner DJ, Miller DC, Mitchell RS, Alderman EA, Popp RL. When should Doppler-determined valve area be better than the Gorlin formula? Variation in hydraulic constants in low flow states. $F$ Am Coll Cardiol 1987; 9:1294-305.

5 Cannon JD, Zile MR, Crawford FA, Carabello BA. Aortic valve resistance as an adjunct to the Gorlin formula in assessing the severity of aortic stenosis in symptomatic patients. F Am Coll Cardiol 1992;20:1517-23.

6 Burwash IG, Pearlman AS, Kraft CD, Miyake-Hull C, Healy NL, Otto CM. Flow-dependence of measurements of aortic stenosis severity during exercise. $f \mathrm{Am}$ Coll Cardiol 1994;24:1342-50.

7 Burwash IG, Thomas DD, Sadahiro M, et al. Dependence of Gorlin formula and continuity equation valve areas on transvalvular volume flow rate in valvular aortic stenosis. Circulation 1994;89:827-35.

8 Casale PN, Palacios IF, Abascal VM, et al. Effects of dobutamine on Gorlin and continuity equation valve areas and valve resistance in valvular aortic stenosis. $\mathrm{Am} \mathcal{f}$ Cardio 1992;70:1175-9.

9 Dow JW, Levine HD, Elkin M, et al. Studies of congenital heart disease IV. Uncomplicated pulmonary stenosis. Circulation 1950;1:267-87.

10 Silber EN, Prec O, Grossman N, Katz LN. Dynamics of isolated pulmonary stenosis. Am $\mathcal{f}$ Med 1951;10:21-6.

11 Ford LE, Feldman T, Chiu YC, Carroll JD. Haemodynamic resistance as a measure of functional impairment in aortic valvular stenosis. Circ Res 1990;66:1-7.

12 Roger VL, Seward JB, Oh JK, Mullany CJ. Is valve resistance a useful index of the severity of aortic stenosis? Doppler-surgical correlation in 407 patients (abstract). Eur Heart $f$ 1995;16:262.

13 Bermejo J, Garcia-Fernandez MA, Torrecilla MEG, et al. Effects of dobutamine on echo-Doppler-derived indexes Effects of dobutamine on echo-Doppler-derived indexes (abstract). Eur Heart $\mathcal{f} 1995 ; 16: 262$.

14 Abascal VM, Wilkins GT, Choong CY, Block PC, Palacios IF, Weyman AE. Mitral regurgitation after percutaneous balloon mitral valvuloplasty in adults: evaluation by pulsed Doppler echocardiography. $\mathcal{F}$ Am Coll Cardiol 1988;11:257-63.

15 Otto CM, Pearlman AS, Comess KA, Reamer RP, Janko CL, Huntsman LL. Determination of the stenotic aortic valve area in adult using Doppler echocardiography. $\mathcal{F}$ Am Coll Cardiol 1986;7:509-17.

16 Hatle L, Angelsen B, Tromsdal A. Noninvasive assessment of atrioventricular pressure half-time by Doppler ultrasound. Circulation 1979;60:1096-104.

17 Folland ED, Parisi AF, Carbone C. Is peripheral arterial pressure a satisfactory substitute for ascending aortic pressure when measuring aortic valve gradients? $f \mathrm{Am}$ Coll Cardiol 1984;4:1207-12.

18 Sprigings DC, Chambers JB, Cochrane T, Allen J, Jackson $\mathrm{G}$. Ventricular stroke work loss: validation of a method of an aortic formula. $\mathcal{f ~ A m ~ C o l l ~ C a r d i o l ~ 1 9 9 0 ; 1 6 : 1 6 0 8 - 1 4 . ~}$ 
19 Martin TW, Moody JM, Abascal VM, et al. Effect of exercise on indices of valvular aortic stenosis. Cathet Cardiovasc Diagn 1992;25:265-71.

20 Bache RJ, Wang Y, Jorgensen ER. Haemodynamic effects of exercise in isolated valvular aortic stenosis. Circulation 1971;44:1003-13.

21 Chambers JB, Sprigings DC, Cochrane T, et al. Continuity equation and Gorlin formula compared with directly observed orifice area in native and prosthetic aortic valves. Br Heart $\mathcal{F} 1992 ; 67: 193-9$

22 Montarello JK, Perakis AC, Rosenthal E, et al. Normal and stenotic human aortic valve opening: in vitro assessment of orifice area changes with flow. Eur Heart $₹$ 1990;11: 484-91.

23 Otto CM, Pearlman AS, Kraft CD, et al. Physiological changes with maximal exercise in asymptomatic valvular aortic stenosis assessed by Doppler echocardiography. $\mathcal{F}$ Am Coll Cardiol 1992;20:1160-7. 


\section{LETTERS TO THE EDITOR}

Scope

Heart welcomes letters commenting on papers published in the journal in the previous six months. Topics not related to papers published earlier in the journal may be introduced as a letter: letters reporting original data may be sent for peer review.

\section{Presentation}

Letters should be:

- not more than 600 words and six references in length

- typed in double spacing (fax copies and paper copy only)

- signed by all authors.

They may contain short tables or a small figure. Please send a copy of your letter on disk. Full instructions to authors appear in the January 1997 issue of Heart (page 89).

Prospective relations between Helicobacter pylori infection, coronary heart disease and stroke in middle-aged men

SIR,-In our nested case-control study of Helicobacter pylori infection and coronary heart disease, ${ }^{1}$ based on the British Regional Heart Study cohort, men with pre-existing coronary heart disease were unintentionally under-represented among the controls selected ( $4 \% \vee 21 \%$ expected). This problem has been documented in the Lancet $^{2}$ in relation to a parallel study of the relation between homocysteine and stroke. However, the results of the study of $H$ pylori and its associations with coronary heart disease and stroke are not materially affected by this under-representation. This is emphasised by the results presented in the paper showing that the odds ratio associated with $H$ pylori infection for coronary heart disease was very similar if men with pre-existing disease were completely excluded. Our conclusion therefore remains unchanged.

PH WINCUP DALI IJ PERRY DP STRACHAN $M$ WALKER Department of Primary Care and Population Sciences Royal Free Hospital School of Medicine, Rowlands Hill Street, London NW3 2PF

1 Whincup PH, Mendall MA, Perry IJ, Strachan DP, Walker M. Prospective relations between Helicobacter pylori infection, coronary heart disease and stroke
men. Heart 1996;75:568-72.

2 Perry IJ. Serum homocysteine and risk of stroke [letter]. Lancet 1996;348:1526.

3 Perry IJ, Refsum H, Morris RW, Ebrahim SB Ueland PM, Shaper AG. Prospective study of serum total homocysteine concentration and risk of stroke in middle-aged British men. Lancet 1995;346:1395-8.

Probable right ventricular dysplasia and patent foramen ovale presenting with cyanosis and clubbing in a patient with characteristics of Noonan syndrome

SIR,-I report additional information on a case described by myself and $\mathrm{Da}$ Costa. The patient, who presented with cyanosis and clubbing, was described as having probable right ventricular dysplasia associated with patent foramen ovale. She also had characteristics of Noonan syndrome. Right ventricular endomyocardial biopsy specimens showed fibre hypertrophy, vacuolation, and degeneration with fine interstitial fibrosis; however, fatty infiltration was not seen. Despite the presence of one major criterion for diagnosis of right ventricular dysplasia (severe dilatation and reduced ejection fraction of the right ventricle without left ventricular impairment), and one minor criterion ( $T$ wave inversion in leads V1-V4 on ECG), there were insufficient criteria for definitive diagnosis of right ventricular dysplasia. $^{2}$

The original report pointed out that the patchy nature of fatty infiltration in the right ventricle can result in failure of endomyocardial biopsies to sample an area of fatty infiltration. Thus, the criteria used for diagnosis often prevents diagnosis during the patient's life; they are later confirmed at post mortem examination to have right ventricular dysplasia

Our patient has since undergone righ ventricular cardiomyopathy with closure of the foramen ovale (by Professor Sir Magdi Yacoub) with clinical benefit. Transmura biopsies taken at that time from the left ventricle were normal. Right ventricular biopsies showed no myocardial tissue bu extensive fibrous and fatty tissue (personal communication, Dr $\mathrm{M}$ Burke, consultan histopathologist, Mount Vernon Hospital, Middx). This additional information confirms that the patient satisfied the criteria for a diagnosis of right ventricular dysplasia. PETER WILMSHURST Royal Shrewsbury Hospital, Mytton Oak Road Shrewsbury $S Y 38 X Q$

1 Wilmshurst P, Da Costa P. Probable right ventricular dysplasia and patent foramen ovale presenting with cyanosis and clubbing in patient with characteristics of Noonan syndrome. Br Heart ₹ 1995;74:471-5.

2 McKenna WJ, Thiene G, Nava A, Fontaliran F, Blomstrom-Lundqvist C, Fontain G, et al, on behalf of the Task Force of the Workin Group Myocardial and Pericardial Disease of the European Society of Cardiology and of the Scientific Council on Cardiomyopathies of the International Society and Federation of the Internation of Cardiology, supported by the Schoepfe Association. Diagnosis of arrhythmogenic right ventricular dysplasia.
$B r$ Heart $₹ 1994 ; 71: 215-8$.

Echocardiographic evaluation of ventricular diastolic function: implications for treatment

SIR,-In their recent editorial Brecker and Gibson suggest an alternative approach to assessing the effects of treatment in diastolic dysfunction, namely to identify changes in diastolic measurements occurring with treatment that are known to increase exercise tolerance or improve prognosis.

Although exercise limitation is the obvious outcome for patients with clinically sig nificant diastolic dysfunction and indeed any functional limitation is likely to be more evident on exercise, nearly all studies report on resting parameters of diastolic performance. Despite increasingly widespread use of stress echocardiographic data in the definition of myocardial ischaemia, systolic dysfunction, and exercise related valve dysfunction, the role of exercise based echocardiographic indices of cardiac relaxation have to date been largely ignored. The reason for this is unclear.

Studies conducted during exercise may increase our ability to define abnormal relaxation and both link this directly to impairment of exercise capacity and assess the effects of candidate treatments. We have previously assessed the effects of brain natriuretic peptide (BNP) infusion on exercise haemodynamics in isolated diastolic dysfunction. ${ }^{2}$ We found that BNP significantly attenuated the exercise induced rise in pulmonary capillary wedge pressure in patients with diastolic dysfunction. In this study, we used invasive haemodynamic monitoring but it is our belief that exercise diastolic performance can be assessed non-invasively with Doppler echocardiography. To achieve this, non-invasive echocardiographic surrogate measures of ventricular filling pressure on exertion need to be explored and validated. $P$ SHIELS RJ MACFADYEN PO LIM TM MACDONALD Department of Clinical Pharmacology Ninewells Hospital $\mathcal{E}$ Medical School,
Dundee, DD1 $9 S Y$

1 Brecker SJD, Gibson DG. Echocardiographic evaluation of ventricular diastolic function implications for treatment. Heart 1996;76 386-7.

2 Clarkson PBM, MacFadyen RJ, Wheeldon NM, MacDonald TM. Effects of brain natriuretic peptide on exercise haemodynamics and neurohormones in isolated diastolic heart failure. Circulation 1996;93:2037-42.

\section{CORRECTIONS}

Fludrocortisone in the treatment of hypotensive disorders in the elderly

RM Hussain, Sf McIntosh, $\mathcal{f}$ Lawson, $R A$ Kenny (Heart 1996;76:507-9).

Under "Interventions" in the abstract it should have read: Fludrocortisone in daily doses of $100 \mu \mathrm{g}(72 \%), 50 \mu \mathrm{g}(27 \%)$, and $200 \mu \mathrm{g}$ (one patient). And not as published.

Effects of increasing flow rate on aortic stenotic indices: evidence from percutaneous transvenous balloon dilatation of the mitral valve in patients with combined aortic and mitral stenosis

T-M Lee, S-F Su, M-F Chen, C-S Liau, Y-T Lee (Heart 1996;76:490-4).

Dr Sheng-Fang Su's name was misspelled in the article.

NOTICES

The 1997 Annual Conference of the British Cardiac Society will take place at G-MEX, Manchester from 20-22 May. For further information, please contact the British Cardiac Society, 9 Fitzroy Square, London W1P 5AH. (Tel: +(0) 171383 3887; fax: +(0) 171388 0903; e-mail: bcs@rbh.nthames.nhs.uk) or visit «http:// www.bcs.rbh.nthames.nhs.uk $\gg$ on the Internet.

Asian-Pacific Cardiovascular Update will be held from June 5-6 in Hong Kong For further information, contact Professor JE Sanderson, Department of Medicine, Prince of Wales Hospital, Chinese University of Hong Kong. (e-mail: jesanderson@cuhk.edu.hk). 